\title{
Long-term evolution of magnetospheric current systems during storms
}

\author{
N. Yu. Ganushkina ${ }^{1}$, T. I. Pulkkinen ${ }^{1}$, M. V. Kubyshkina ${ }^{2}$, H. J. Singer ${ }^{3}$, and C. T. Russell ${ }^{4}$ \\ ${ }^{1}$ Finnish Meteorological Institute, Geophysical Research Division,P.O. Box 503, FIN-00101 Helsinki, Finland \\ ${ }^{2}$ Institute of Physics, University of St.-Petersburg, St.-Petersburg,198904, Russia \\ ${ }^{3}$ NOAA Space Environment Center, Boulder, CO 80303-3328, USA \\ ${ }^{4}$ Institute of Geophysics and Planetary Physics, University of California, Los Angeles, CA 90095-1567, USA
}

Received: 20 May 2003 - Revised: 7 October 2003 - Accepted: 28 October 2003 - Published: 2 April 2004

\begin{abstract}
We present a method to model the storm-time magnetospheric magnetic field using representations of the magnetic field arising from the various magnetospheric current systems. We incorporate the effects of magnetotail changes during substorms by introducing an additional localized thin current sheet into the Tsyganenko T89 model. To represent the storm-time ring current the T89 ring current is replaced by a bean-shaped current system, which has a cross section that is close to the observed distribution of trapped particles in the inner magnetosphere and has an eastward flowing inner and westward flowing outer components. In addition to the symmetric ring current, an asymmetric partial ring current is taken into account with closing Region 2 sense field-aligned currents. Magnetopause currents are varied in accordance with solar wind dynamic pressure variations. Three moderate geomagnetic storms when $D_{s t}$ reached about $-150 \mathrm{nT}$ and one big storm with $D_{s t}$ about $-250 \mathrm{nT}$ are modelled. The model free parameters are specified for each time step separately using observations from GOES 8 and 9, Polar, Interball and Geotail satellites and $D_{s t}$ measurements. The model gives a high time-resolution field representation of the large-scale magnetic field, and a very good reproduction of the $D_{s t}$ index. It is shown that the ring current is most important during intense storms, whereas the near-Earth tail currents contribute more to the $D_{s t}$ index than the ring current during moderate storms.
\end{abstract}

Key words. Magnetospheric physics (Current systems; Magnetospheric configuration and dynamics; Storms and substorms)

\section{Introduction}

Many changes occur in the Earth's magnetosphere during magnetic storms, including changes in different current systems, and, hence, in the magnetic field. During the last decades several magnetospheric magnetic field models have been developed. One of the first ones for modelling of the storm-time magnetic field was a nonstationary paraboloid model proposed by Alekseyev (1978); Alexeev et al. (1996, 2001). This model contains dipole, magnetopause, tail and ring current sources and is able to calculate the magnetic field from them separately. The model contains five timedependent input parameters: geomagnetic dipole tilt angle, distance to the subsolar point, distance to the earthward edge of the magnetospheric tail current sheet, geotail lobe magnetic flux, and intensity of the ring current perturbation field at Earth. Except for dipole tilt, none of these parameters are direct observables, they are defined by the solar wind density and velocity, the strength and direction of interplanetary magnetic field and auroral $A L$ index. In the latest version (Alexeev et al., 2001), new analytical relations describing the dynamics of different magnetic field sources dependent on input parameters were introduced.

The most widely used models are the empirical Tsyganenko models based on tens of years of satellite data. In the earlier versions, T87 and T89 (Tsyganenko, 1987, 1989), the data set was divided into six subsets, corresponding to six $K_{p}$-values, ranging from 0 to $>5$. Separate sets of model parameters were found for each $K_{p}$-bin. Magnetospheric configurations corresponding to average conditions are quite well represented, whereas fine structure in the magnetic field during substorms or large magnetic field changes during storms cannot be accounted for by these models (Ganushkina et al., 2002b).

In a later version T96 (Tsyganenko, 1995) the components of the model field were considered as functions of the spatial coordinates, dipole tilt angle, IMF $B_{y}$, IMF $B_{z}$, solar wind 
dynamic pressure, and $D_{s t}$. In the latest version T01 (Tsyganenko, 2002a, b), an attempt was made to take into account the prehistory of the solar wind introducing two functions $G_{1}$ and $G_{2}$ in the parametrization of the tail field term that depends on IMF $B_{z}$ and solar wind velocity and their time history. Whereas these models are much more flexible in representating different magnetospheric configurations, the model parameters determining the current configurations were fitted to the entire data set and hence situations occurring only rarely in the data set are still not well represented.

Several types of studies require an accurate representation of the magnetospheric configuration during a specific event. It is the magnetospheric configuration that determines how particles move in the magnetosphere, and changes in that configuration provide the particle acceleration. For such cases, event-oriented modelling may be of key importance (Ganushkina et al., 2002a, b, c). Event-oriented models contain free parameters whose values are evaluated from observations for each separate time period. We have introduced a model, where the T89 model was modified by introducing a "bean"-shaped axially symmetric ring current with a cross section close to the observed distribution of trapped particles and by varying the intensity of the tail current according to the changes associated with substorm activity. The model free parameters were set by fitting to in-situ field observations and the $D_{s t}$ index. When compared to the T89 or T96 models, this event-oriented model is in better agreement with the observed magnetic field and the $D_{s t}$ index.

In this paper we further develop the event-oriented modelling and discuss the dynamics of magnetic storms using the model results. Instead of the axially symmetric ring current model (Ganushkina et al., 2002b, c), we introduce an asymmetric model including partial ring current and fieldaligned currents closing in the ionosphere. We account for the substorm changes in the magnetospheric tail by adding a localized thin current sheet to the model, and the magnetopause currents are adjusted to solar wind dynamic pressure changes. We model four storm events: the period of 2-4 May 1998, contained two storms, $D_{s t}=-85 \mathrm{nT}$ on 2 May and $D_{s t}=-250 \mathrm{nT}$ on 4 May. During both 10-12 October 1997, and 6-9 November 1997, $D_{s t}$ reached about $-150 \mathrm{nT}$. We examine the long-term evolution of different current systems during storm times and compute the relative contributions from the ring, magnetotail and magnetopause currents to the $D_{s t}$ index.

\section{Storm-time magnetic field modelling}

\subsection{Ring current}

The ring current model consists of symmetric and asymmetric parts. The symmetric ring current has eastward and westward components. Both eastward and westward currents have a "bean-shaped" crosssection that is close to the observed distribution of trapped particles (Ganushkina et al., 2002b). The current density is axially symmetric relative to the $Z$ axis in geocentric solar magnetic $(S M)$ coordinates.

In the equatorial plane $Z=0$ the current density distribution is given by a Gaussian distribution

$J\left(R_{e q}\right)= \pm J_{0} \exp \left[-\frac{\left(R_{e q}-R_{0}\right)^{2}}{2 \sigma_{R_{e q}}{ }^{2}}\right]$,

where $R_{e q}^{2}=X^{2}+Y^{2}, J_{0}$ is the maximum current density at $R_{e q}=R_{0}, \sigma_{R_{e q}}$ is the half-width of the current density distribution, and + (-) sign corresponds to westward (eastward) current.

The current density at a point $\mathbf{R}$ outside the equatorial plane is given by the functional dependence of omnidirectional flux along the field line (Roederer, 1970)

$J\left(B / B_{0}\right)=J\left(R_{e q}\right)\left(B / B_{0}\right)^{-A / 2}$,

where $B$ is the magnetic field at $\mathbf{R}$ and $B_{0}$ is the magnetic field at the equator. A dipole magnetic field is used for tracing the magnetic field lines. Latitudinal dependence of the current density is given by the anisotropy index $A / 2$. If $A=0$, the particle distribution is isotropic along the field lines. Increasing $A$ leads to particle distributions concentrated closer to the equator.

The total current density of the symmetric ring current is a sum of eastward and westward current densities

$$
\begin{aligned}
& J\left(\mathbf{R}, B / B_{0}\right)^{\mathrm{SYM}}= \\
& -J_{\text {0east }} \cdot \exp \left[-\frac{\left(R_{e q}-R_{\text {0east }}\right)^{2}}{2 \sigma_{R_{e q}}{ }^{2}}\right]\left(B / B_{0}\right)^{-A / 2} \\
& +J_{0 \text { west }} \cdot \exp \left[-\frac{\left(R_{e q}-R_{0 \text { west }}\right)^{2}}{2 \sigma_{R_{e q}}{ }^{2}}\right]\left(B / B_{0}\right)^{-A / 2} .
\end{aligned}
$$

This symmetric ring current is fully defined by six parameters: the mean radius of the maximum current density for eastward and westward components ( $R_{0 \text { east }}$ and $\left.R_{0 \text { west }}\right)$, the maximum current density for eastward and westward components ( $J_{0 \text { east }}$ and $J_{0 \text { west }}$ ), the width of the Gaussian distribution $\left(\sigma_{R}\right)$, and the anisotropy index $(A)$. The last two parameters are assumed to be the same for the eastward and westward components.

The asymmetric ring current model contains a partial ring current, together with closing field-aligned currents flowing from the ionosphere at dawn and into the ionosphere at dusk, which corresponds to the Region 2 field-aligned current direction. The local time dependence is given by

$$
\begin{gathered}
J\left(\mathbf{R}, B / B_{0}, \phi\right)^{\mathrm{ASYM}}= \\
J_{0 \text { part }} \exp \left[-\frac{\left(R_{e q}-R_{0 \text { part }}\right)^{2}}{2 \sigma_{R_{e q}}^{2}}\right] \times \\
\left(B / B_{0}\right)^{-A / 2} \cdot[1-\cos (\phi-\delta)],
\end{gathered}
$$

where $J_{0 \text { part }}$ is the maximum current density reached at $R_{e q}=R_{0 \text { part }}$ at longitude $\phi=180^{\circ}$. Such $\cos$-dependence of local time variations of the ring current was also used by Tsyganenko (2002a). Addition of this asymmetric ring current 
to the symmetric ring current produces day-night asymmetry in the ring current distribution. The phase $\delta$ represents the dawn-dusk asymmetry of the ring current such that positive values of the angle $\delta$ shifts the maximum current density towards dusk.

We define the ring current system on a grid $(R$, lat, lon $)$ in spherical coordinates, where $R$ is in the range of $1-8 R_{E}$, lat $=\left(-90^{\circ}, 90^{\circ}\right)$ and $l o n=\left(0^{\circ}, 360^{\circ}\right)$ with the number of gridpoints of $50 \times 100 \times 100$, respectively. These grid points span the space where the model ring current flows. In order to attribute each grid element a value of the current, we integrate the current density $J$ through a surface dS in the vicinity of the grid element. To obtain the magnetic field at a given point, we calculate the contributions from all current elements.

As the total current density needs to be divergenceless, the local time asymmetry of the current gives rise to fieldaligned currents. At each grid point, the difference in current density between neighboring points is evaluated. A fieldaligned current along dipole field lines into $(\Delta J<0)$ or out from $(\Delta J>0)$ the ionosphere is used to close the perpendicular current. Finally, the magnetic field from this current system is calculated using the Biot-Savart law.

The asymmetric ring current is defined by three parameters: the mean radius of the maximum current density ( $\left.R_{0 \text { part }}\right)$, the maximum current density ( $\left.J_{0 \text { part }}\right)$, and the phase $\delta$, giving the dawn-dusk asymmetry. The parameters $\sigma_{R}$ and $A$ are assumed to be the same as for the symmetric part.

Figure 1 shows schematically the isolines of (a) $j_{y}$ in the noon-midnight meridional plane and (b) $j_{R}=\sqrt{j_{x}^{2}+j_{y}^{2}}$ in the equatorial plane for a symmetric ring current (left panel), corresponding to quiet conditions and an asymmetric ring current (right panel) for disturbed conditions. The blue color indicates current flowing into and red color currents out from the plane. Eastward and westward flowing components of the ring current are present both for quiet and disturbed conditions. Asymmetry is pronounced on the nightside. The parameters used to create this plot were $R_{0 \text { east }}=2 R_{E}, R_{0 \text { west }}=4 R_{E}, \sigma_{R}=0.8, A=1$, and $J_{0 \text { east }}=1.5 \mathrm{nA} / \mathrm{m}^{2}, J_{0 \text { west }}=3 \mathrm{nA} / \mathrm{m}^{2}$ for the symmetric case and $R_{0 \text { part }}=6 R_{E}, J_{0 \text { part }}=2 \mathrm{nA} / \mathrm{m}^{2}$ and $\delta=0^{\circ}$ for the asymmetric case.

\subsection{Addition of a new tail current sheet}

For the tail current system we introduce both global and local changes. Global changes include intensification of the tail current sheet as a whole using a tail current amplification factor $(1+A T S)$ (Ganushkina et al., 2002b). This factor indicates the change in the tail current from the original value, i.e. that given by Tsyganenko T89 $K_{p}=4$, to values both lower $(A T S<0)$ and higher $(A T S>0)$ than the standard model. A new, thin tail current sheet is added to account for the local changes. The azimuthal component $A^{T}$ of the vector potential giving the tail current sheet in the Tsyganenko
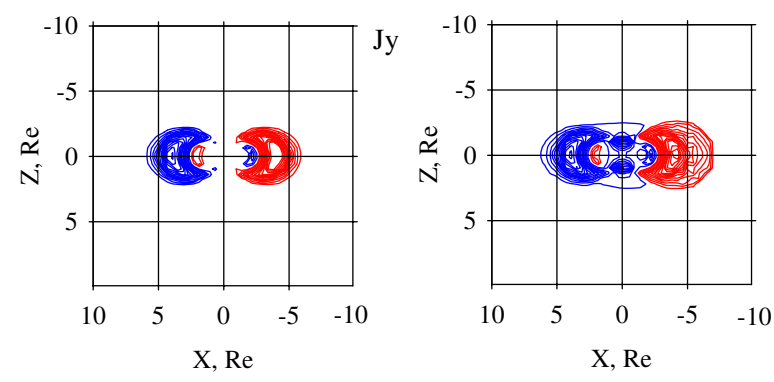

(a)
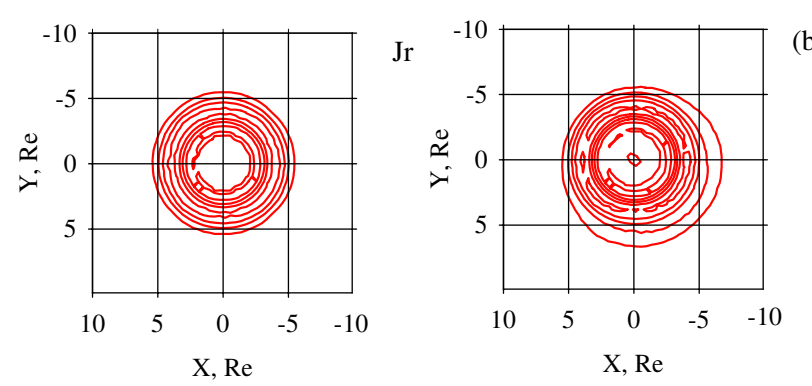

(b)

Fig. 1. The isolines of (a) $j_{y}$ in the noon-midnight meridional plane and $j_{R}=\sqrt{j_{x}^{2}+j_{y}^{2}}$ in the equatorial plane for symmetric ring current (left panel) corresponding to quiet conditions and asymmetric ring current (right panel) for disturbed conditions. Blue color indicates current flowing into and red color currents out from the plane.

T89 model has the form:

$$
\begin{aligned}
A^{T}= & \frac{W(x, y)}{S_{T}\left(z, a_{T}, D_{0}\right)+a_{T}+\xi_{T}\left(z, D_{0}\right)} \times \\
& \left(C_{1}+\frac{C_{2}}{S_{T}\left(z, a_{T}, D_{0}\right)}\right)
\end{aligned}
$$

where $C_{1}$ and $C_{2}$ are the coefficients which define the current distribution in the central current sheet, $a_{T}$ is the radial scale length which defines the geocentric distance to the current density maximum, and $D_{0}$ is the half-thickness of the current sheet in the central magnetotail region (for details, see Tsyganenko (1989)). The truncation factor $W(x, y)$ is given in SM coordinates by

$$
\begin{gathered}
W(x, y)=0.5\left(1-\frac{x-x_{0}}{\left[\left(x-x_{0}\right)^{2}+D_{x}{ }^{2}\right]^{1 / 2}}\right) \times \\
\left(1+y^{2} / D_{y}{ }^{2}\right)^{-1},
\end{gathered}
$$

where $x_{0}$ is the coordinate which defines the location of the region of steepest decrease of $W(x, y), D_{x}$ and $D_{y}$ are the scale lengths corresponding to variations of $W(x, y)$ along $X$ - and $Y$-directions.

We introduce two vector potentials,

$$
\begin{aligned}
& A_{1}^{T}=\frac{W_{1}(x, y)}{S_{T}+a_{T}+\xi_{T}}\left(C_{1}+\frac{C_{2}}{S_{T}}\right) \quad \text { and } \\
& A_{2}^{T}=\frac{W_{2}(x, y)}{S_{T}+a_{T}+\xi_{T}}\left(C_{1}+\frac{C_{2}}{S_{T}}\right),
\end{aligned}
$$




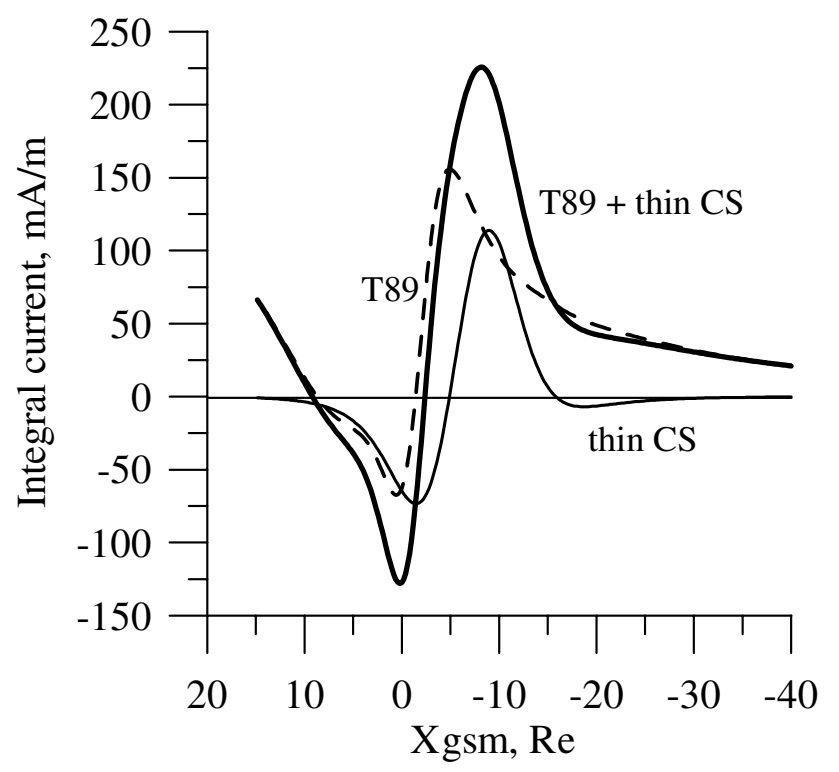

Fig. 2. $x_{\mathrm{GSM}}$-dependence of the integral current for the T89 model $K_{p}=4$ (dotted line), for the additional, relatively thin current sheet (thin solid line), and the combined T89 model with the added thin current sheet (thick solid line).

where the truncation factors are

$W_{1}(x, y)=$
$A_{n t c}\left(1-\frac{x-x_{1 n t c}}{\left[\left(x-x_{1 n t c}\right)^{2}+D_{x}{ }^{2}\right]^{1 / 2}}\right) \times\left(1+y^{2} / D_{y}{ }^{2}\right)^{-1}$

and

$W_{2}(x, y)=$
$A_{n t c}\left(1-\frac{x-x_{2 n t c}}{\left[\left(x-x_{2 n t c}\right)^{2}+D_{x}^{2}\right]^{1 / 2}}\right) \times\left(1+y^{2} / D_{y}{ }^{2}\right)^{-1}(8)$

The difference $A^{T}{ }_{1}-A^{T} 2$ gives a vector potential characterized by a finite $x$-scale; it is zero outside $25 R_{E}$. Furthermore, this vector potential produces a relatively thin current sheet. The current sheet is defined by four parameters: the amplitude $A_{n t c}$, which defines the thin current sheet intensity, $x_{1 n t c}$ and $x_{2 n t c}$ determine the spatial distribution of functions $W_{1}$ and $W_{2}$ and give the points of steepest increase of these functions, and the half-thickness of the current sheet $\left(D_{0}\right)$. Other parameters are as in the T89 tail current module.

Figure 2 shows the $x_{\mathrm{GSM}}$-dependence of the Z-integrated current for the T89 model $K_{p}=4$ (dotted line), and for the additional thin current sheet (thin solid line). The thick solid line shows the combined T89 model and the additional thin current sheet. When the thin current sheet is added to T89 model, the integrated current maximum value is increased and its position is shifted tailward. The combination of the global variation of the tail current and the added new thin current sheet makes it possible to account for the magnetic field changes associated with substorms during the storm.
Table 1. Model parameters.

\begin{tabular}{ccc}
\hline Ring current & Tail current & Magnetopause currents \\
\hline$R_{0 \text { east }}$ & $A T S$ & $R_{T}$ \\
$R_{0 \text { west }}$ & $A_{\text {ntc }}$ & $A M P$ \\
$R_{0 \text { part }}$ & $x_{1 \mathrm{ntc}}$ & \\
$J_{0 \text { east }}$ & $x_{2 \text { ntc }}$ & \\
$J_{0 \text { west }}$ & $D_{0}$ & \\
$J_{0 \text { part }}$ & & \\
$\sigma_{R}$ & & \\
$A$ & & \\
$\delta$ & & \\
\hline
\end{tabular}

\subsection{Magnetopause currents}

The magnetopause moves inward during increased solar wind dynamic pressure. To adjust for this, the magnetic field of the Chapman-Ferraro currents $B_{C F_{T 89}}$ at the magnetopause given by T89 $K_{p}=4$ model was scaled by $B_{C F}=\chi^{3} B_{C F_{T 89}}$, where $\chi=\left(P_{d} /<P_{d}>\right)^{k}, k=1 / 6, P_{d}$ is the solar wind dynamic pressure, and $\left\langle P_{d}\right\rangle=2 \mathrm{nPa}$ (Tsyganenko, 2002b). Self-similar compression/expansion of the magnetopause in response to changes in $P_{d}$ and scaling of its linear dimensions by the factor $\chi$ allow us to make a similar scaling for field components. The scaling parameter $A M P=\chi^{3}$ is directly determined from solar wind pressure variations.

In the T89 model, the parameter $R_{T}$ defines the characteristic scale size of the magnetotail. In the T89 $K_{p}=4$ model its value is $R_{T}=30 R_{E}$. Using this model with zero tilt angle we determined the "magnetopause" position $Z_{T, T 89}$ at $X_{\mathrm{GSM}}=-20 R_{E}$ and $Y_{\mathrm{GSM}}=0$. We then determined the magnetopause position as given by Shue et al. (1998) model $Z_{T, \text { Shue }}$, using the observed solar wind and IMF parameters. The magnetotail size is then modified by changing the value of $R_{T}$ to $30 R_{E} \cdot Z_{T, \text { Shue }} / Z_{T, T 89}$. As the magnetopause position in the Shue et al. (1998) model depends on the solar wind dynamic pressure and IMF $B_{z}$, the $R_{T}$ parameter is thus defined by the observed solar wind and IMF parameters.

Table 1 lists the model parameters for the three current systems: the ring current, the tail current, and the magnetopause currents.

\subsection{Modelling procedure}

For modelling the storm events we use the Tsyganenko T89 $K_{p}=4$ magnetic field model as a baseline. This version of T89 model represents very disturbed condition of the magnetospheric magnetic field and gives correct average largescale magnetospheric configuration. If we need higher $K_{p}$ versions of T89, there is a $K_{p}=5$ version but the number of magnetic field data points in this $K_{p}$ interval when the model was constructed is not sufficiently large. Table 2 summarizes the model parameters. We set the eastward ring current at $R_{0 \text { east }}=2 R_{E}$ with an intensity $J_{0 \text { east }}=1.5 \mathrm{nA} / \mathrm{m}^{2}$ in 
accordance to Lui et al. (1987) study where AMPTE/CCE data were used to obtain perpendicular current characteristics during storms. The width of the Gaussian distribution $\sigma_{R}=0.8$ and the anisotropy index $A / 2=1$ are used for all three components of the ring current representation. The $\sigma_{R}=0.8$ gives the rate of increase (decrease) in current density distribution so that all the notable current would be included in between 2 and $6 R_{E} . A / 2=1$ was set following the Garcia and Spjeldvik (1985) study on anisotropy of particle distribution, and it means that current density is concentrated near the equator and decreases away from the equator. For the additional thin current sheet we set $x_{1 n t c}=-2.0 R_{E}$, $x_{2 n t c}=-10.0 \mathrm{R}_{\mathrm{E}}$, and $D_{0}=0.2 R_{E}$. With these values of parameters for the additional thin current sheet the total tail current starts to deviate from the T89 value at about $-5 R_{E}$, and returns back to T89 value after $-15 R_{E}$ (see Fig. 2).

Three parameters are computed from the observed solar wind data and $D_{s t}$ index. In the partial ring current representation, the parameter $\delta$ defining the duskward rotation depends on the corrected ring current index $D_{s t}^{*}: \delta=\frac{\pi}{2} \tanh \frac{\left|D_{s t}^{*}\right|}{D s t_{0}^{*}}$, where $D s t_{0}^{*}=41.6 \mathrm{nT}$ (Tsyganenko, 2002b). The scaling parameter $A M P$ for the magnetic field of the magnetopause currents and the scale size of the magnetotail $R_{T}$ were obtained from the solar wind data as described above.

The free parameters in the model, which are marked by bold font in Table 2, are the radius of the westward ring current ( $\left.\mathbf{R}_{\mathbf{0 w e s t}}\right)$ and partial ring current ( $\left.\mathbf{R}_{\mathbf{0 p a r t}}\right)$ and the maximum current densities for westward ( $\mathbf{J}_{\mathbf{0 w e s t}}$ ) and partial ( $\left.\mathbf{J}_{\mathbf{0 p a r t}}\right)$ ring currents, the amplification factor for the tail current (ATS), and the amplitude of additional thin current sheet intensity $\left(\mathbf{A}_{\mathbf{n t c}}\right)$. We then searched the values of the free parameters that give the best fit between the model and the in-situ magnetic field observations by GOES 8, GOES 9, Polar, Geotail and Interball satellites (obtained from the Coordinated Data Analysis Web (CDAWeb) and DARTS at the Institute of Space and Astronautical Science (ISAS) in Japan), and the $D_{s t}$ measurements (obtained from the World Data Center C2 for Geomagnetism, Kyoto).

The details of the fitting procedure are the following (Ganushkina et al., 2002b): The search procedure is initiated from different sets of initial values of the model parameters randomly generated using the Monte-Carlo method. The set of parameters which gave the minimum error between the model and the observed magnetic field values was selected as the starting point. After that, one of the parameters was varied while others were held fixed, in order to find the parameter value that gave the minimum error between the model and the observations. Next, using the optimum value for that parameter, the next parameter was varied. The procedure was repeated for all free parameters. As a result, we obtain a set of parameters corresponding to the minimum error between observations and model. The procedure was repeated once more, but the parameters were varied in the vicinity of the previously obtained values, with a smaller step size to better localize the minimum. The possibility of finding a local
Table 2. Model parameters for storm event modelling.

\begin{tabular}{|c|c|c|}
\hline Current system & Parameter & Status \\
\hline Eastward ring current & $\begin{array}{c}R_{0 \text { east }} \\
J_{0 \text { east }} \\
\sigma_{R} \\
A / 2\end{array}$ & $\begin{array}{c}2 R_{E} \\
1.5 \mathrm{nA} / \mathrm{m}^{2} \\
0.8 \\
1\end{array}$ \\
\hline Westward ring current & $\begin{array}{c}\mathbf{R}_{\mathbf{0 w e s t}} \\
\mathbf{J}_{\mathbf{0 w e s t}} \\
\sigma_{R} \\
A / 2\end{array}$ & $\begin{array}{c}2.5-4.5 R_{E} \\
1.5-15 \mathrm{nA} / \mathrm{m}^{2} \\
0.8 \\
1\end{array}$ \\
\hline Partial ring current & $\begin{array}{c}\mathbf{R}_{\mathbf{0 p a r t}} \\
\mathbf{J}_{\mathbf{0 p a r t}} \\
\sigma_{R} \\
A / 2 \\
\delta\end{array}$ & $\begin{array}{c}5-6.5 R_{E} \\
0.5-7 \mathrm{nA} / \mathrm{m}^{2} \\
0.8 \\
1 \\
\text { from } D s t^{*}\end{array}$ \\
\hline Tail current & $\begin{array}{c}\text { ATS } \\
\mathbf{A}_{\text {ntc }} \\
x_{1 \text { ntc }} \\
x_{2 \text { ntc }} \\
D_{0}\end{array}$ & $\begin{array}{c}-0.5-2 \\
0.1-2.4 \\
-2 R_{E} \\
-10 R_{E} \\
0.2 R_{E}\end{array}$ \\
\hline Magnetopause currents & $\begin{array}{c}A M P \\
R_{T}\end{array}$ & $\begin{array}{c}\text { from } \mathrm{SW} \\
\text { from } \mathrm{SW} \text { and IMF }\end{array}$ \\
\hline
\end{tabular}

rather than a global minimum is reduced by combining two methods: first, the Monte-Carlo method that gives a random distribution of parameter values and then, the minimization procedure. Furthermore, the error value was controlled for each step of the calculations.

To obtain the model $D_{s t}$ index, the magnetic field from the extraterrestrial currents was computed at the locations of several stations such as Sun Juan, Tenerife, Tbilisi, Lunping, Kakioka, Honolulu and Del Rio. However, before the model values can be compared with the observed ones, the quiet time level must be subtracted from the model. This is done by modelling the entire duration of the quietest day of the month for each storm event. The quiet level of the magnetic field given by the model is then evaluated at the locations of $D_{s t}$ stations. In order to be able to examine the contributions of the different current systems to the $D_{s t}$ index, the quiet-time levels are also evaluated for the ring, tail and magnetopause currents separately. Currents in the magnetosphere induce currents in the electrically conducting Earth, which are estimated to be about $25 \%$ of the measured $D_{s t}$ (Häkkinen et al., 2002). In comparing our model $D_{s t}$ with the observed one, we remove this $25 \%$ from the observed $D_{s t}$.

\section{Description of events}

We selected four storms for our modelling: 2 May 1998, 4 May 1998, 10-12 October 1997, and 6-9 November 1997. Interplanetary magnetic field and solar wind data were obtained from WIND spacecraft. 

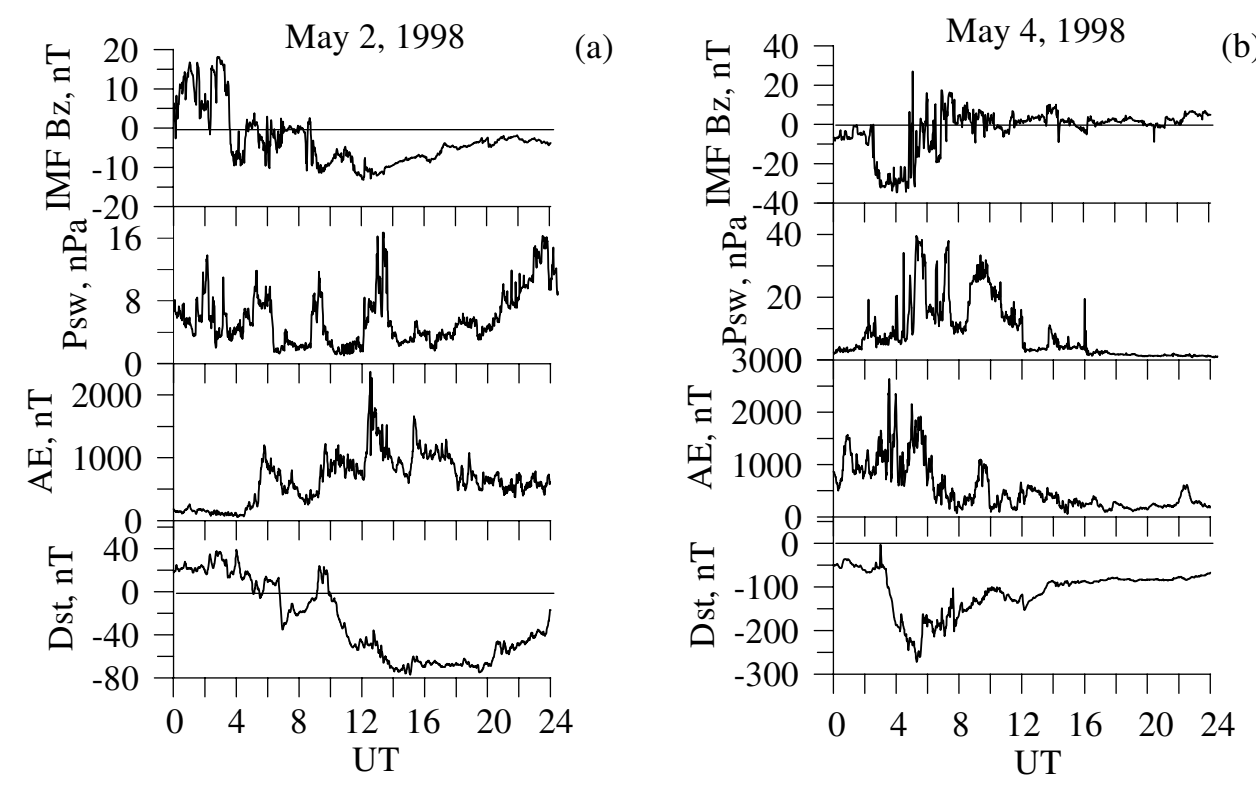

(b)

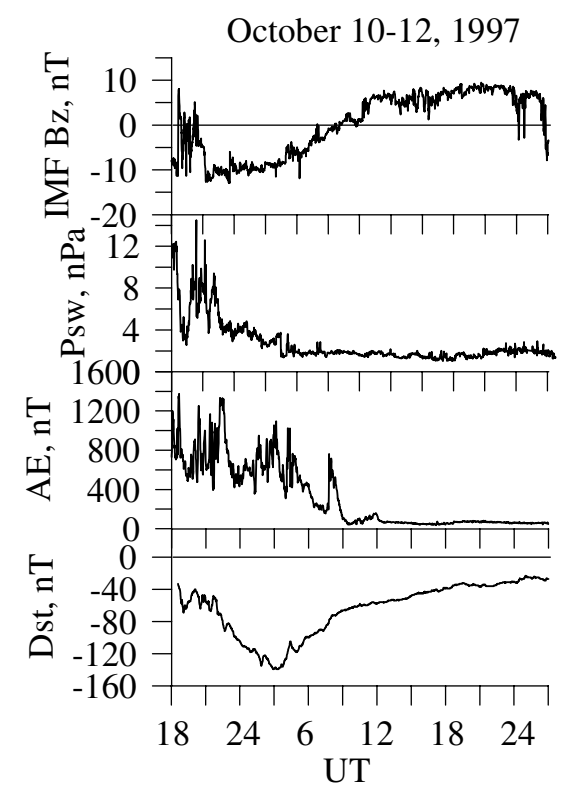

(c)

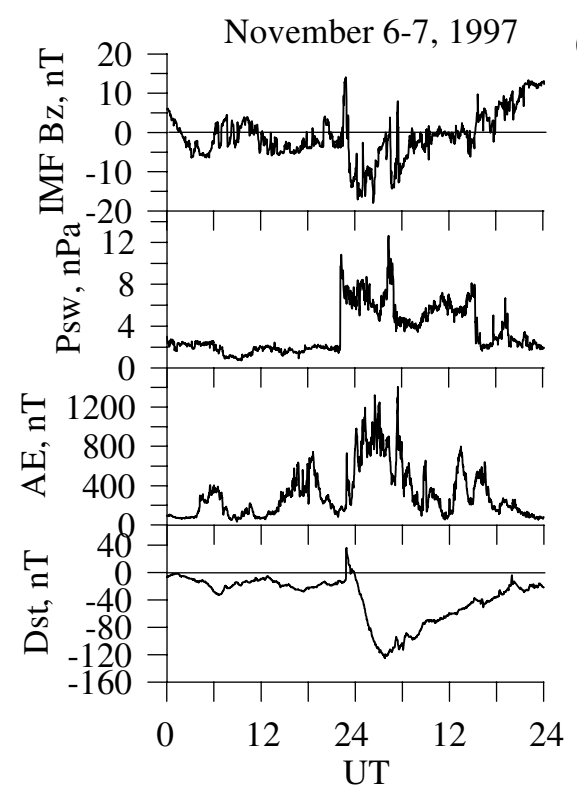

Fig. 3. Overviews (panels from top to bottom in each figure: IMF $B_{z}$ and $P_{s w}$ as measured by WIND spacecraft, $A E$ and $D_{s t}$ ) of four storm events that occurred on (a) 2 May 1998, (b) 4 May 1998, (c) 10-12 October 1997, and (d) 6-9 November 1997.

The storms in early May 1998 were initiated from an extended period of solar activity which started on 29 April 1998. There were several coronal mass ejections during the period: on 29 April (17:00 UT), 1 May (23:40 UT), 2 May (05:30 UT) and 4 May (02:00 UT). The activity on 2 May 1998 (Fig. 3a) was driven by a magnetic cloud, whose effects were first seen at about 03:35 UT, when IMF $B_{z}$ turned southward. There were several pressure pulses reaching up to about $15 \mathrm{nPa}$. The magnetospheric response was seen as a strong increase in the $A E$ index that reached over 20:00 nT at about 12:00 UT. The $D_{s t}$ index reached about $-80 \mathrm{nT}$ at 15:00 UT and recovered to the level of about $-50 \mathrm{nT}$ by the end of the day.
The strongest period of activity occurred on 4 May (Fig. 3b), when $B_{z}$ decreased sharply at about 02:30 UT down to $-30 \mathrm{nT}$, remained at that level for about three hours, and then increased and fluctuated around zero until the end of the day. The solar wind dynamic pressure was at its highest at about $40 \mathrm{nPa}$ around 04:00 UT and $30 \mathrm{nPa}$ around 08:00 UT. As shown by Russell et al. (2000), during the period between 04:00-08:00 UT, the magnetopause crossed the geosynchronous orbit repeatedly, getting as close as $5 R_{E}$ in the subsolar region. The $A E$ index reached over $2000 \mathrm{nT}$ around 04:00 UT. $D_{s t}$ decreased to $-250 \mathrm{nT}$, followed by a slow recovery toward a more quiet-time state. 
The storm on 10-12 October 1997 was moderate in intensity (Fig. 3c). The IMF $B_{z}$ remained negative $(-12 \mathrm{nT})$ until about 10:00 UT on 11 October. A solar wind dynamic pressure peak of about $10 \mathrm{nPa}$ was detected at about 22:00 UT on 10 October. The $A E$ index showed several peaks with more than 1000 nT magnitude during the main phase and storm maximum. $D_{s t}$ reached $-140 \mathrm{nT}$ at about 03:00 UT on October 11 and recovered to $-20 \mathrm{nT}$ by the end of the day.

A storm of about similar intensity occurred on 6-7 November 1997 (Fig. 3d). On 6 November $B_{z}$ fluctuated around zero and dropped to $-15 \mathrm{nT}$ at the end of the day around 23:00 UT. Solar wind dynamic pressure was about $3 \mathrm{nPa}$ during 6 November and increased up to about $10 \mathrm{nPa}$ at about 22:00 UT. The $A E$ index had several peaks, with the highest magnitude of about $1000 \mathrm{nT}$ at the beginning of 7 November. $D_{s t}$ reached $-120 \mathrm{nT}$ at about 04:00 UT on 7 November and recovered to $-20 \mathrm{nT}$ by the end of the day.

Figure 4 shows the evolution of orbits of satellites such as GOES 8 (red curve), GOES 9 (blue curve), Polar (green curve), Geotail (pink curve) and Interball (purple curve), during the time periods when the magnetic field data was used for modelling storm events on (a) 2 May 1998, (b) 4 May 1998, (c) 10-12 October 1997, and (d) 6-9 November 1997.

\section{Model results}

\subsection{Magnetic field and $D_{s t}$ index}

Figure 5 shows the model results for the storm on 2 May 1998. The $B_{x}$ and $B_{z}$ components (GSM coordinates) of the external magnetic field are shown in solid black lines for GOES 8 (a, b), GOES 9 (c, d), and Polar (e, f). The $B_{y}$ is not shown since the $B_{x}$ and $B_{z}$ components represent the most changes in the main current systems occurring during storm times, and our model does not include separate representation for field-aligned currents. Our storm time model is shown in red and the Tsyganenko T89 model for $K_{p}=4$ in green. Bottom panel $(\mathrm{g})$ shows the measured $D_{s t}$ index (black line) and $D_{s t}$ as calculated using our storm time model (red line). Figure 6 shows the results for the 4 May 1998 storm in the same format as Fig. 5.

Figure 7 shows the measured and modeled magnetic field in the same format as Fig. 5, with the addition of the $B_{x}$ and $B_{z}$ components of the external magnetic field from Geotail $(\mathrm{g}, \mathrm{h})$ and $B_{x}$ component from Interball (i) for the 10-12 October 1997 storm event. The $B_{z}$ component from Interball was not available during this time. Figure 8 shows the model results for the 6-7 November 1997 storm in the same format as Fig. 7.

Our storm-time magnetic field model reproduces the observed $D_{s t}$ index almost perfectly for all modeled storms. The $B_{z}$ component at geostationary orbit is also quite well reproduced, including the substorm-associated changes. Model curves for $B_{z}$ component follow quite closely the observed ones also at Polar, Geotail and Interball. On the other hand, our model cannot fit well the observed large variations in the $B_{x}$ component. The large observed $B_{x}$ values imply the existence of intense currents that can be either fieldaligned or perpendicular, or an even stronger compression of the magnetosphere than that represented by the magnetopause current intensification in our model.

\subsection{Model parameters}

Figure 9 shows the time evolution of the model parameters. The four plots show the results for the four storm events (in each figure): symmetric ring current intensity (pink line) and total ring current intensity including symmetric and partial components (red line), together with variation of the $D_{s t}$ index (black line), tail current intensity (blue line), together with the $A E$ index (black line), and amplification factor for magnetopause current $A M P$ (green line) with the observed solar wind dynamic pressure (black line).

The ring current intensity tends to follow the $D_{s t}$ index. Our model produces a very sharp and large increase in the ring current intensity during the storm main phase on 4 May 1998, when the relative role of the ring current in $D_{s t}$ also strongly increases. The tail current responds with its intensity increase to substorm activity represented by the $A E$ index. The amplification factor for the magnetopause current magnetic field $A M P$ was computed from solar wind dynamic pressure, which is reflected in the similar temporal evolution of the two curves.

Maximum tail current intensity value ranged from about $10 \cdot 10^{6}$ A on 2 May 1998 to $20 \cdot 10^{6}$ A on 4 May 1998 . On the other hand, maximum ring current intensity was around $3 \cdot 10^{6}$ A during all three moderate storms, but during the intense storm on 4 May 1998, the ring current intensity was $11 \cdot 10^{6} \mathrm{~A}$, sometimes reaching values higher than the tail current.

The partial ring current plays a significant role. The total ring current intensity was $3 \cdot 10^{6} \mathrm{~A}$ for moderate storm maximum and $10 \cdot 10^{6} \mathrm{~A}$ for intense storm maximum. At the same time, the symmetric ring current values were $1.8 \cdot 10^{6} \mathrm{~A}$ and 3.9. $10^{6} \mathrm{~A}$, respectively.

\subsection{Contributions to $D_{s t}$ index}

The model allows us to calculate the contributions of tail, ring and magnetopause currents to the $D_{s t}$ index. Quiet time contributions for each current system were computed first. Figure 10 shows an example of contributions from the ring current (red line), the tail current (blue line) and the magnetopause currents (green line) to the observed $D_{s t}$ index (black line) during 29 November, the quietest day of November 1997. The lower panel shows the observed $D_{s t}$ (black panel), together with the model $D_{s t}$ (red line) given as the sum of the contributions from the tail, ring, and magnetopause currents. Note that for this quiet day the tail and magnetopause currents compensate each other, and the $D_{s t}$ index truly represents the ring current. Average quiet time contributions were $-1.12 \mathrm{nT}$ for the ring current, $-16.3 \mathrm{nT}$ for the tail current and $15.43 \mathrm{nT}$ for the magnetopause currents. The 

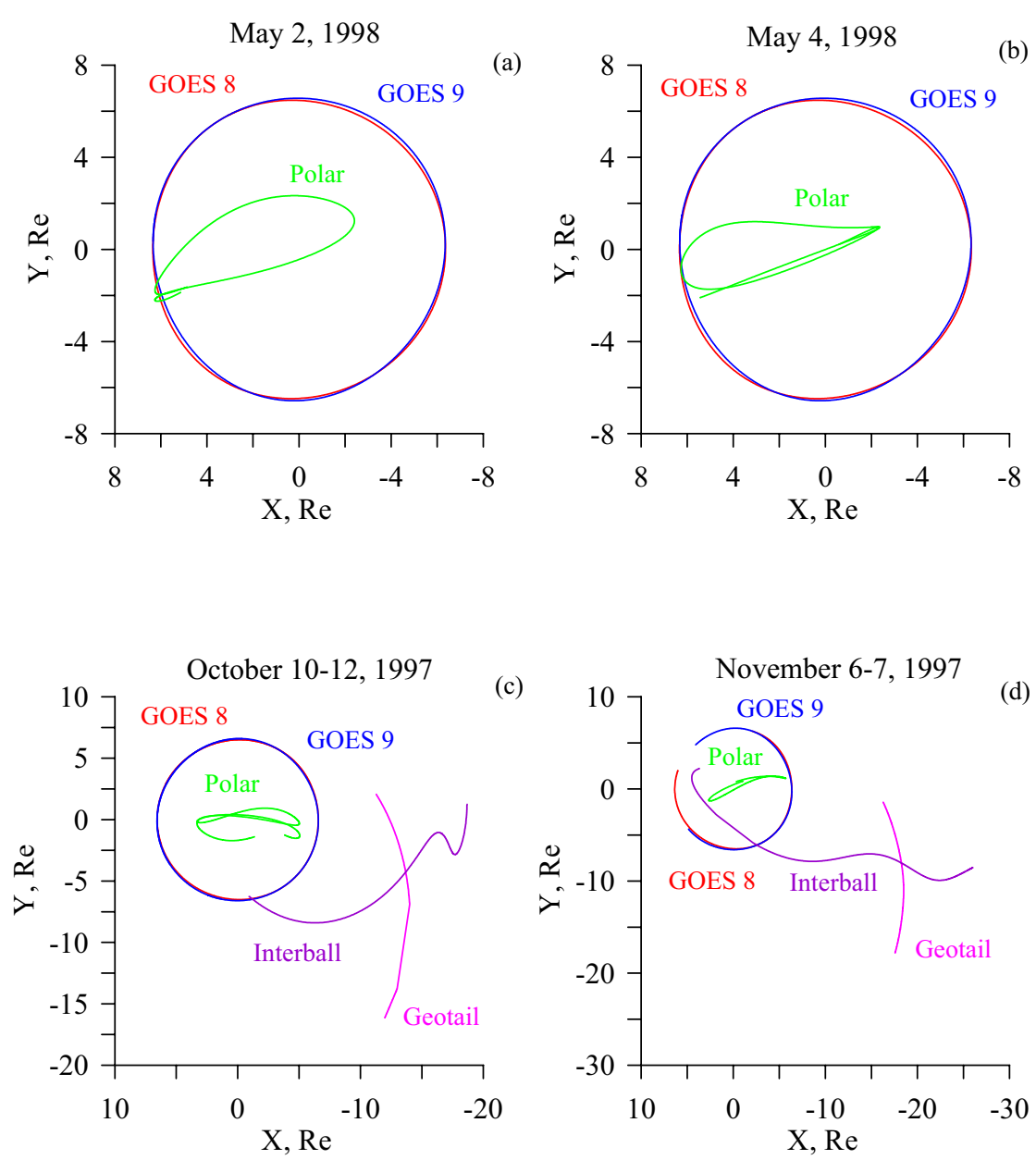

Fig. 4. Evolution of orbits of satellites during the time periods when the magnetic field data was used for modelling storm events on (a) 2 May 1998, (b) 4 May 1998, (c) 10-12 October 1997, and (d) 6-9 November 1997.

obtained model values for the quiet time ring current were 0.2 to $3 \mathrm{nA} / \mathrm{m}^{2}$, which is in agreement with previous observations (Lui and Hamilton, 1992) and modelling (Milillo et al., 2003).

Figure 11 shows contributions from the ring current (red line), tail current (blue line) and magnetopause currents (green line) to the observed $D_{s t}$ index (black line) during the four storm events. For the two consecutive storms on 2 May and 4 May 1998, it is clear that the contributions from different current systems to the $D_{s t}$ index change during the storm development: the ring current contribution gradually increases and reaches maximum at the intense storm maximum, whereas the tail current contribution does not show a clear increase with storm development on 4 May. During the moderate storm on 3 May, the tail current contributes more than the ring current to the $D_{s t}$. The situation is quite different during the intense storm on 4 May: It is clearly seen that then the main contribution to $D_{s t}$ comes from the ring current. For the 10-12 October 1997 storm, the main contribution to the $D_{s t}$ comes from the tail current after the storm beginning until the maximum. At the beginning of the recovery phase the ring current becomes dominant and remains dominant until the end of the storm. During the entire 6-7 November 1997 storm, the main contribution to $D_{s t}$ index comes from the tail current. These results suggest that the relative contributions from different current systems to the $D_{s t}$ index depend on the storm intensity such that the ring current dominates during strong storms while the tail current is important during moderate storms. Note that for all storms the tail current intensifies first at the storm beginning when the $D_{s t}$ drops, while the ring current develops later and stays longer at an increased level.

\section{Discussion}

In this paper we discuss model results of the magnetospheric magnetic field evolution during four storm events on 2 May 1998, 4 May 1998, 10-12 October 1997 and 6-7 November 1997. The modelling is an expansion of the technique described previously (Ganushkina et al., 2002b). With the Tsyganenko T89 as a baseline model, we introduced a beanshaped model for the ring current, varied the intensity of the tail current and its closure currents along the nightside 


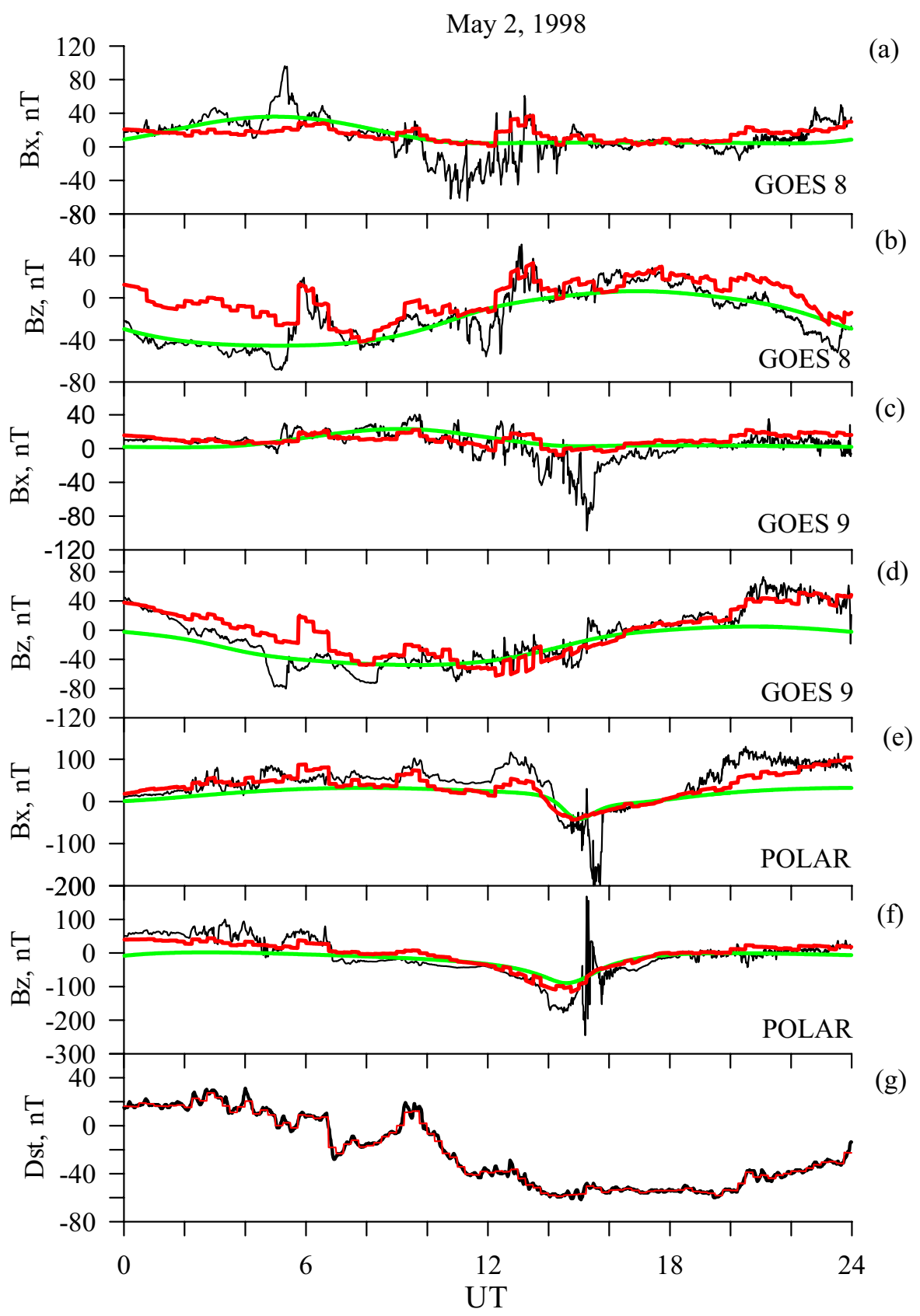

Fig. 5. Modelling results for 2 May 1998 (panels from top to bottom): $B_{x}$ and $B_{z}$ components of the external magnetic field measured (solid black lines) on GOES 8 (a, b) and GOES $9(\mathbf{c}, \mathbf{d})$, on Polar $(\mathbf{e}, \mathbf{f})$, calculated using our storm time model (red lines) and T89 $K p=4$ (green lines), and measured (black line) and calculated (red line) Dst-index (g).

magnetopause, and varied the dayside magnetopause currents. The key new features in this paper are the introduction of an eastward ring current and a partial ring current with closure by Region 2 field-aligned currents, in addition to the westward symmetric ring current. Furthermore, a new timevariable thin cross-tail current has been added to the model. This combination allows us to simultaneously describe the substorm-associated tail field variations and the storm-driven ring current intensity changes. Magnetic field observations by GOES 8, GOES 9, Polar, Geotail and Interball, and the
$D_{s t}$ measurements were used to evaluate the model parameters for each time step individually.

Our empirical model reproduces the measured $B_{z}$ components and the $D_{s t}$ index quite well. Adding the thin current sheet improved the model fit to observations quite significantly, as compared to our previous model without the thin current sheet (Ganushkina et al., 2002b). At the same time, this model still cannot reproduce the observed large variations in the $B_{x}$ component; even adding a quite intense thin current sheet does not help in these cases. It seems to be 


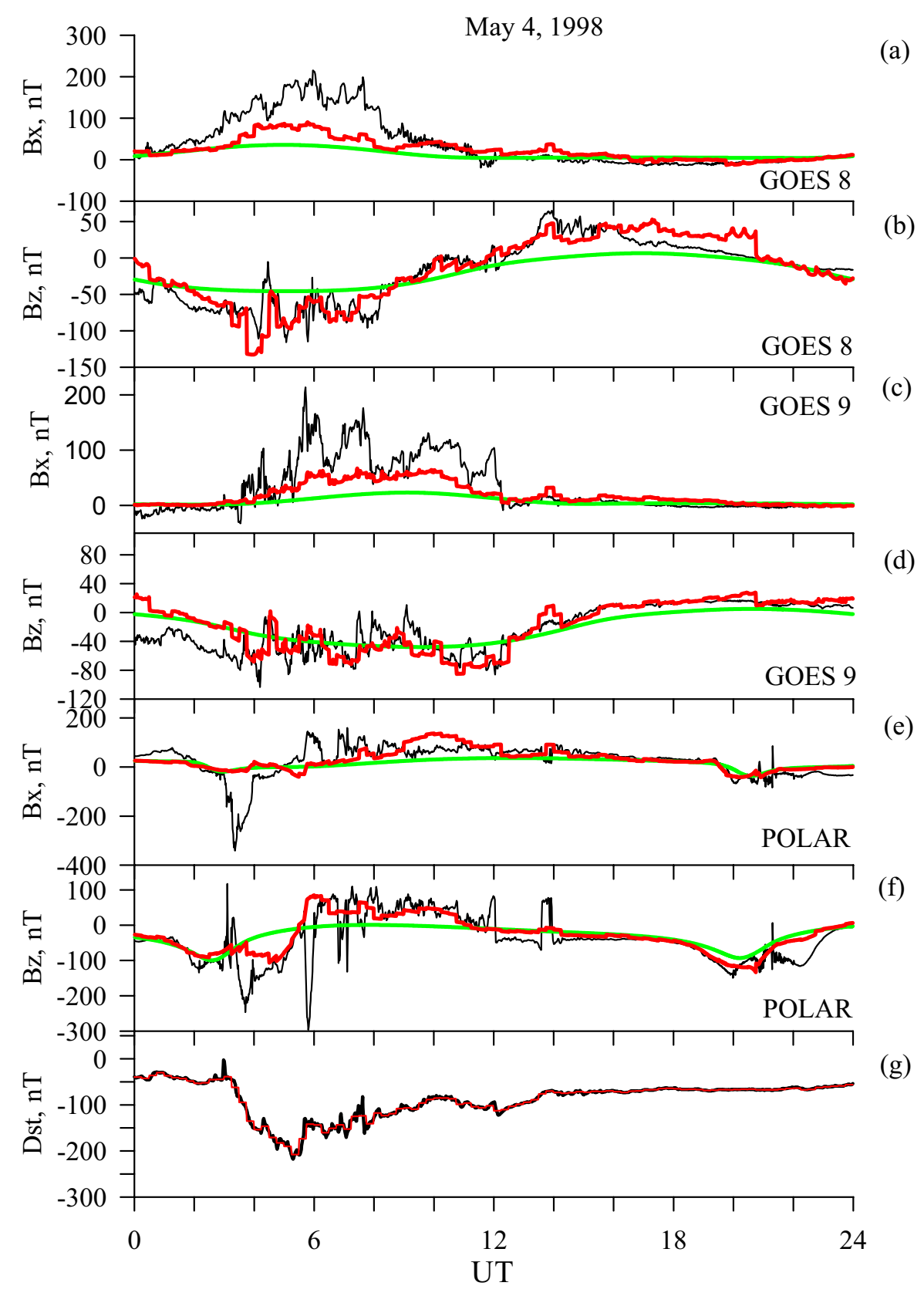

Fig. 6. Same as in Fig. 5 but for 4 May 1998 storm event.

unlikely that large $B_{x}$ values are due to localized current systems, such as field-aligned currents, as $B_{x}$ remains large quite a long time and field-aligned currents typically occupy more narrow region in local time. There is a correspondence between the times when large $B_{x}$ is observed on the nightside and the times when there are peaks in solar wind dynamic pressure (see Fig. 3 and Figs. 5-8). These large $B_{x}$ values are most probably created by strong compression of the magnetosphere, which is only partially represented in the model by the intensification of the magnetopause currents.

The model ring current intensity follows closely the $D_{s t}$ index, which is partly but not totally a consequence of using $D_{s t}$ as input data in the model. Our tail current intensifies as substorm activity represented by the $A E$ index in- creases, but there is no detailed correlation or anti-correlation between the tail current intensity and the $A E$ index. During storm times when the substorm activity is high, reconnection in the midtail keeps feeding plasma into the inner magnetosphere, which moves the inner edge of the plasma sheet further earthward and intensifies the cross-tail current. This process leads to the increase in the model cross-tail current as $A E$ increases. Our tail current intensifies when substorm activity is present mainly during the storm main phase and maximum, and decreases during the storm recovery phase (Fig. 9). The cross-tail current intensity maximum during the storm main phase on 4 May 1998 reached about $20 \cdot 10^{6} \mathrm{~A}$, which is about double the Tsyganenko T89 model for $K_{p}=4$ $\left(12 \cdot 10^{6} \mathrm{~A}\right)$. 


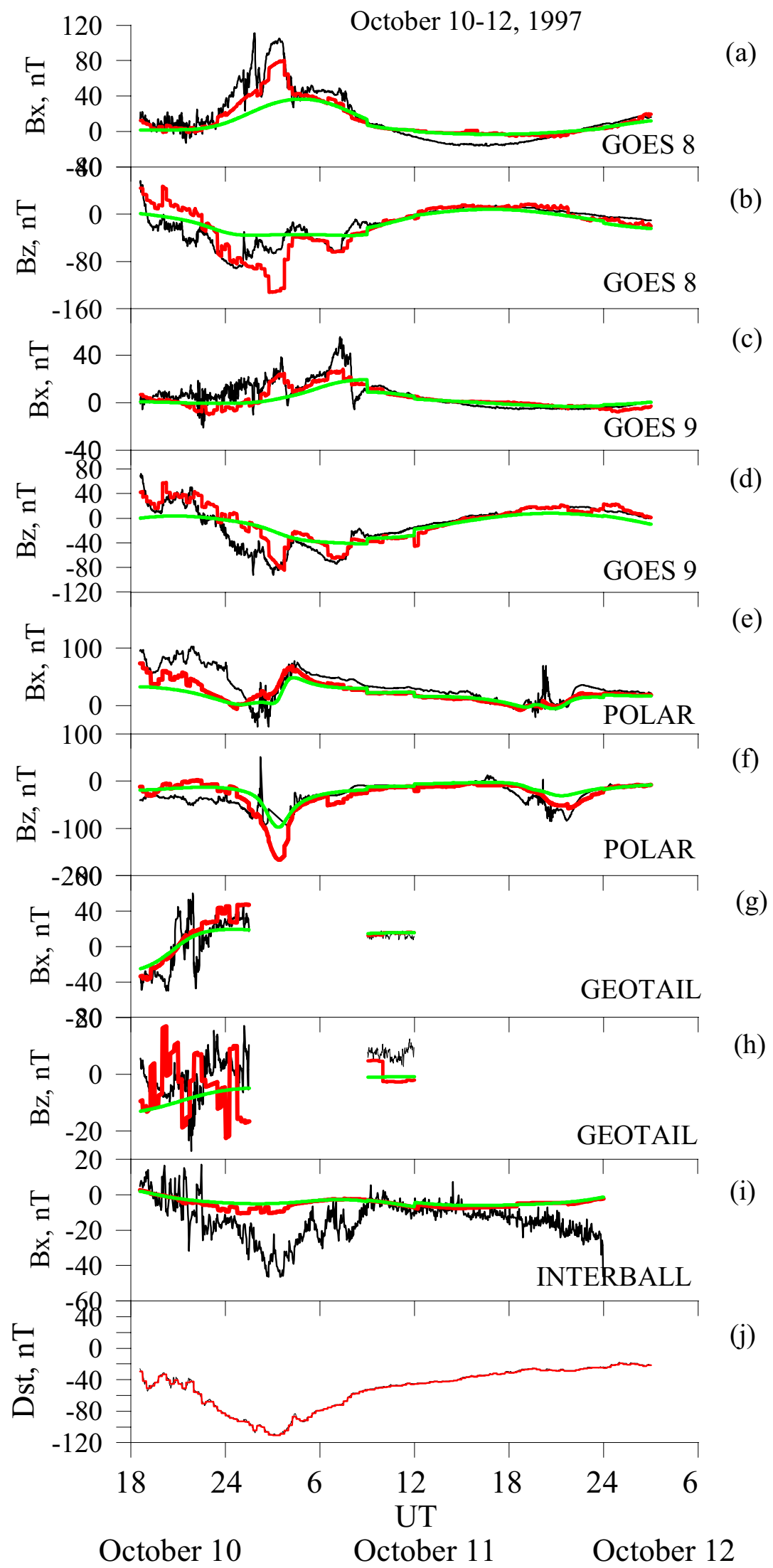

Fig. 7. Same as in Fig. 5 with addition of $B_{x}$ and $B_{z}$ components of the external magnetic field measured and calculated using Geotail (g, h) and Interball (i) data for 10-12 October 1997 storm event. $B_{z}$ from Interball was not available. 


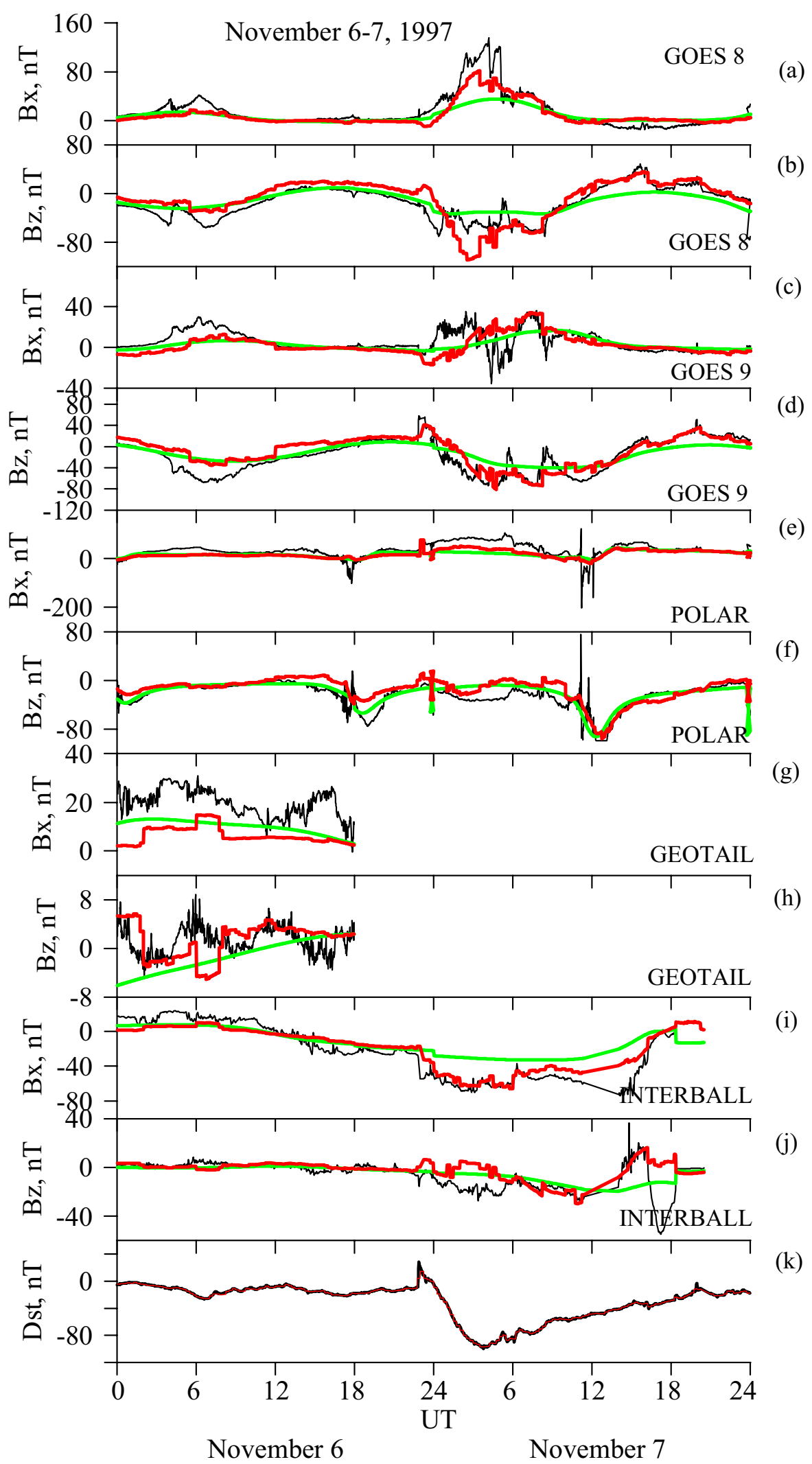

Fig. 8. Same as Fig. 7 but for 6-7 November 1997 storm event. 

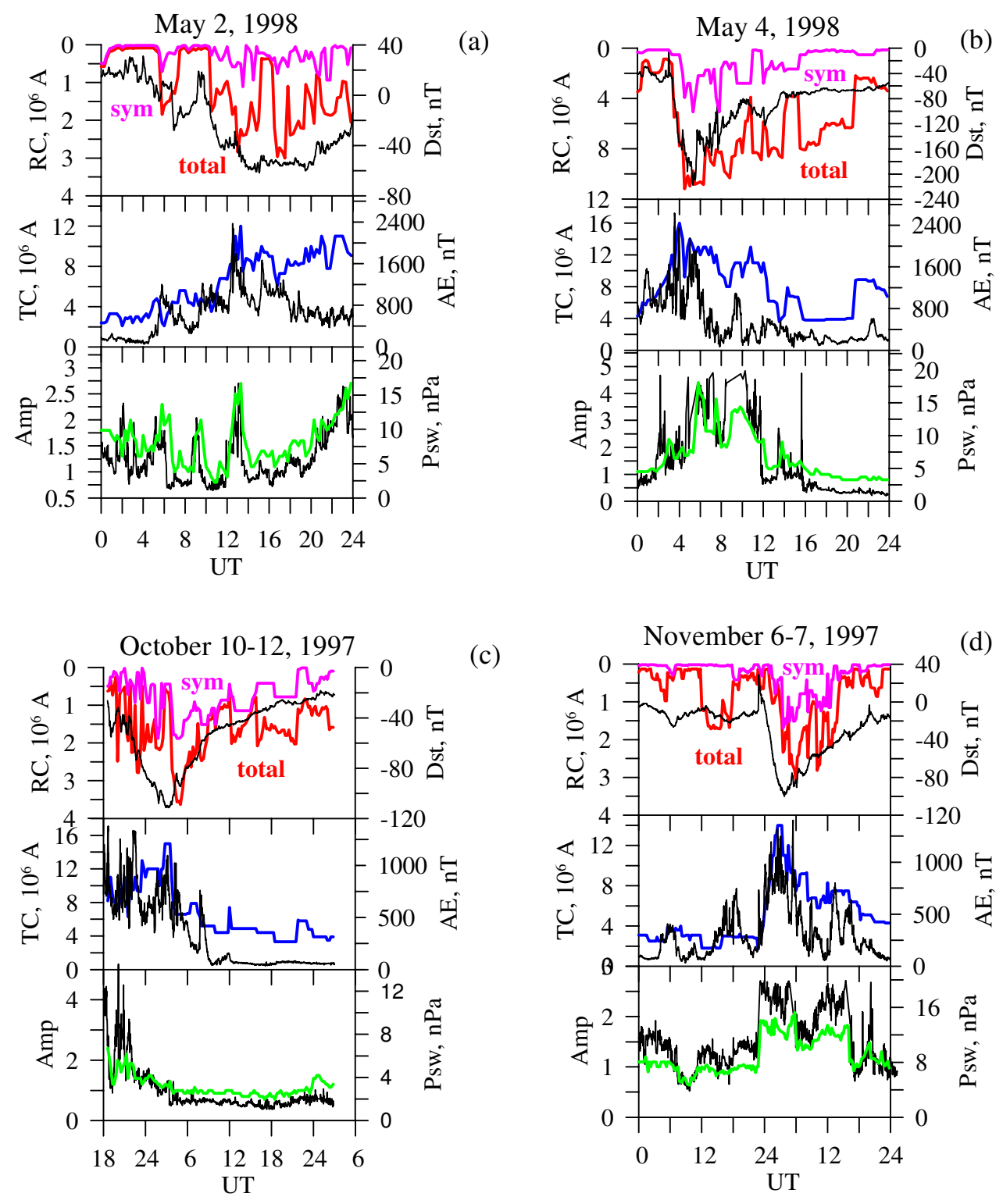

Fig. 9. Time evolution of the model parameters (in each figure): (upper panel) symmetric ring current (pink line) and asymmetric ring current including symmetric and partial components intensity (red line), together with variation of $D_{s t}$ index (black line), (middle panel) tail current intensity (blue line), together with $A E$ index (black line), and (bottom panel) amplification factor for magnetopause current magnetic field AMP (green line) with the observed solar wind dynamic pressure (black line) for (a) 2 May 1998, (b) 4 May 1998, (c) 10-12 October 1997, and (d) 6-9 November 1997 storm events.

The tail currents intensify because of the strong driving (compare Fig. 11 to IMF $B_{z}$ in Fig. 3). As the $A E$ index includes both the driven system, as well as the substormassociated currents, it intensifies strongly as the driving increases. As we are looking at the storm evolution in a rather coarse time resolution, the $A E$ index is the appropriate comparison, and the correlation is positive: the tail currents intensify for increasing $A E$. On the other hand, a more fine time resolution comparison of the substorm-associated cross-tail current variations should show an anti-correlation with the substorm-associated $A E$ index.
When finding the model parameters, we had a time step of $15 \mathrm{~min}$. During that time the model parameters remained constant. Thus, variations with time scales less than $15 \mathrm{~min}$ were not resolved. Our model does not provide a set of instantaneous magnetospheric magnetic field pictures but an evolution of magnetospheric configuration during storms. It is possible to do smaller scale modelling which would represent substorm changes, but, on the other hand, this will lead to the question of how to relate properly the large- and smallscale variations inside one storm-time modelling. 


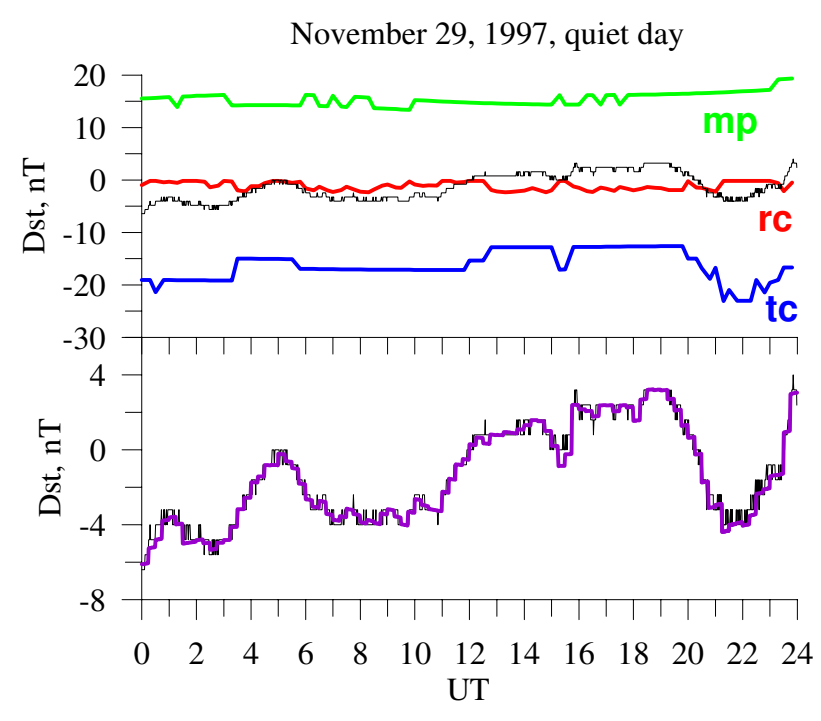

Fig. 10. Contributions from the ring current (red line), the tail current (blue line) and the magnetopause currents (green line) to the observed $D_{s t}$ index (black line) and (lower panel) the observed (black line) and model (purple line) $D_{s t}$ index during 29 November, the quietest day of November 1997.

The eastward ring current at the inner edge provides an improved response of the current changes in the $D_{s t}$ index, while its effects are quite small in the magnetic field measurements of the high-altitude spacecraft. Thus, as the $D_{s t}$ index is a measure of the integrated total intensity of the currents in the magnetosphere, the eastward ring current provides a substantial improvement. The partial ring current in our model is located near the outer edge of the symmetric ring current in the evening sector, and its intensity is thus largely defined by the geostationary orbit magnetic field measurements that record the strongest variations of currents in that region. Our total ring current representation is in agreement with the recent study by Le et al. (2003) on the morphology of the ring current derived from magnetic field observations. Figure 12 illustrates the changes in the model current density in $\mathrm{nA} / \mathrm{m}^{2}$ in the (a) equatorial and (b) noonmidnight meridian planes for three moments during the 4 May 1998 intense storm: (left) before the storm at 01:00 UT, (middle) at the storm main phase at 05:00 UT and (right) during the recovery phase at 10:00 UT. It can be seen how the ring and tail currents intensify and how the ring current becomes asymmetric with maximum near dusk at the storm main phase and recovers its symmetry during the recovery phase. Our model gave the total ring current intensity as $3 \cdot 10^{6} \mathrm{~A}$ for moderate storm maximum and $10 \cdot 10^{6} \mathrm{~A}$ for intense storm maximum, and the symmetric ring current values were $1.8 \cdot 10^{6} \mathrm{~A}$ and $3.9 \cdot 10^{6} \mathrm{~A}$, respectively. This means that a large part ( $40 \%$ and $60 \%$, respectively) of the intensity of the total ring current comes from the partial ring current. On the other hand, as we do not have good local time coverage of the inner magnetosphere magnetic field measurements, the distinction between symmetric and asymmetric parts is sometimes difficult. However, without better cover- age of observations, there is little that can be done to address this ambiguity.

During moderate-intensity storms, the tail current contributed to the $D_{s t}$ index more than the ring current. This result is consistent with the study by Dremukhina et al. (1999), who studied four moderate storms. On the other hand, Turner et al. (2000), using the Tsyganenko T96 magnetospheric magnetic field model to model one moderate January 1997 storm, concluded that the tail current contribution is about $25 \%$ of the measured $D_{s t}$ variation. For 2 May 1998, and 6-7 November 1997, the tail current contribution almost follows the observed $D_{s t}$ index, whereas on 10-12 October, 1997, the ring current is dominant during the storm recovery phase. On 4 May 1998, during the very intense storm, the ring current was dominant and also gave the largest contribution to the $D_{s t}$ index. Comparing the two consequent storms on 2 May and 4 May 1998, the tail current intensification was quite comparable during both storms, while during 4 May the ring current was much more intense than during the 2 May storm. Furthermore, during the 4 May storm, the magnetosphere was in a highly compressed state (Russell et al., 2000), which also contributed to the inner magnetosphere field variations. Thus, during intense storms the main contribution to the $D_{s t}$ index comes from the ring current, but during moderate storms the tail current contribution can be dominant or comparable to the ring current. Our results are similar to earlier work (Alexeev et al., 1996; Dremukhina et al., 1999) with regard to moderate storms, but give a quite different picture of the dynamics during intense storms.

When discussing the relative contributions from the ring and tail currents, the key question is how to separate partial ring current and tail current at the inner edge of the plasma sheet. Alexeev et al. (1996), Dremukhina et al. (1999), and Arykov and Maltsev (1994) assumed that the current flowing in the region at 6-8 $R_{E}$ is a tail current. At the same time, Le et al. (2003) state that current in this region is a partial ring current.

There are two possible ways to give definitions: Using magnetic field observations, current flowing in the region of dipolar field lines is a (partial) ring current while current in tail-like field lines is a cross-tail current. The other way is to measure the characteristic energy of the current-carrying population and assume that it is a ring current (or partial ring current), if the energies are in the range of several tens of $\mathrm{keV}$ and a tail current, if the energies are more typical plasma sheet energies of $10-20 \mathrm{keV}$. In reality, the ring and tail currents cannot be unambiguously separated in this transition region between dipole and tail-like field. Our model uses the observed magnetic field, and it does not contain any predetermined separation between the ring and tail currents in the transition region. If the observed magnetic field is stretched tail-like (which was actually observed at GOES), the model tries to intensify the tail current. Calculations of model contributions to $D_{s t}$ from the parts of the tail current confined in different regions in the tail showed that $40 \%$ of our model tail current contribution to the $D_{s t}$ index comes from the current that flows inside $8 R_{E}$. This region was included in the study 
May 2, 1998
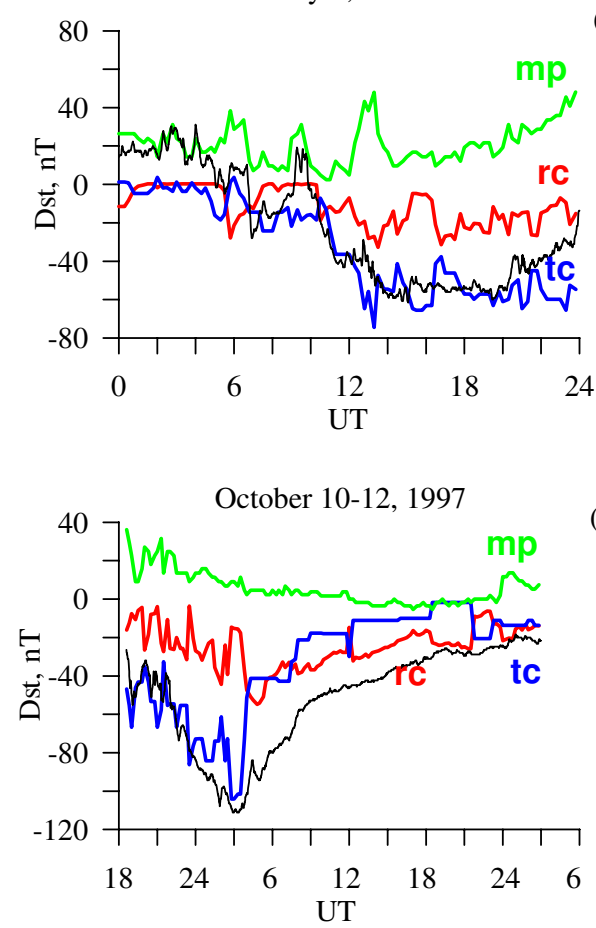

(a)

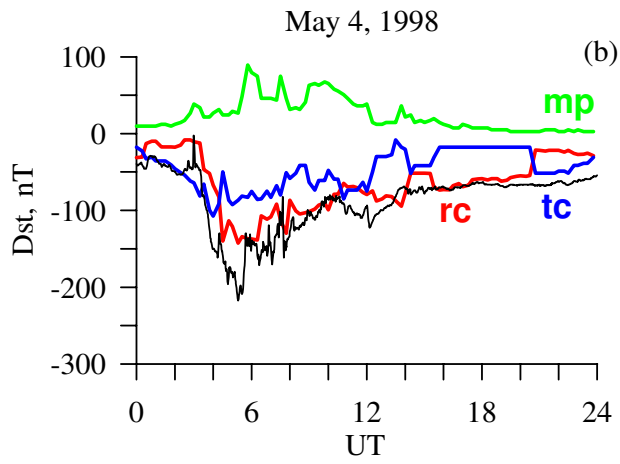

(b)

(c)

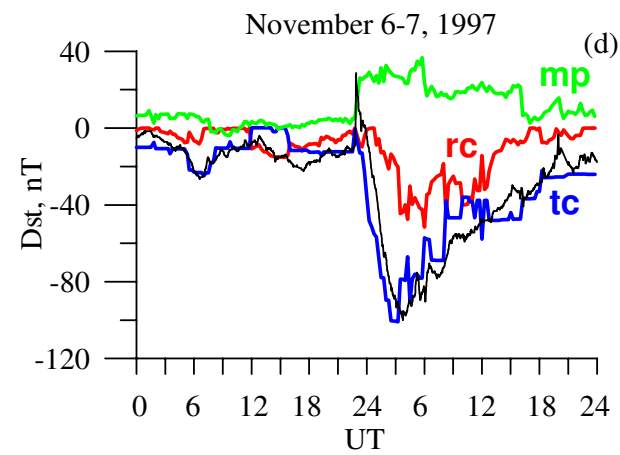

Fig. 11. Contributions from the ring current (red line), the tail current (blue line) and the magnetopause currents (green line) to the observed $D_{s t}$-index (black line) during (a) 2 May 1998, (b) 4 May 1998, (c) 10-12 October 1997, and (d) 6-7 November 1997 storm events.

by Le et al. (2003), and the tail current was not subtracted from the measurements. Therefore, it is important to realize that results indicating strong asymmetric ring current and strong inner-tail current are not contradictory but may be the same physical process described with different terminology.

It is interesting to note that our model current systems have different characteristic response times. While the ring current increases quite slowly (much slower than the $D_{s t}$ enhancement), the tail current responds very rapidly. Thus, most of the fast decrease in the $D_{s t}$ index during the storm main phase in this model is created by the intensifying crosstail current. The ring current intensification contributes to the magnitude and timing of the storm maximum, as the ring current maximizes at storm maximum. Further analysis on the relative contributions to $D_{s t}$ from the different current systems including the ring and tail current contributions during storm recovery phase and the contribution of the magnetopause currents is still needed. In particular, one of the still open issues is how the different solar wind drivers affect the evolution of the magnetospheric current systems: for example, are the current systems during magnetic clouds similar to those produced by highly fluctuating solar wind and IMF conditions (Huttunen et al., 2002)?

The model presented here is an empirical model, where the temporal evolution is determined from the observed magnetic variations. The modelling method is an extension of the work by Pulkkinen et al. (1992), providing an improved time-varying representation of the inner magnetosphere field.
Furthermore, while Pulkkinen et al. (1992) modeled individual substorm phases lasting typically $1-2 \mathrm{~h}$ using a single set of parameter values that changed in a linear manner, here the modelling covers several storms each lasting of the order of $24 \mathrm{~h}$, and the model parameters are defined for each time step individually, with no forced relationship of the parameter values between subsequent time steps.

The intensity of the ring current during storm evolution has also been studied using a complementary approach of computing energetic particle transport in different field geometries, and the ground magnetic disturbance $\left(D_{s t}\right)$ using the Dessler-Parker-Sckopke (Dessler and Parker, 1959; Sckopke, 1966) relationship (see, for example, Chen et al., 1993; Fok and Moore, 1997; Jordanova et al., 1997; Ebihara and Ejiri, 2000; Liemohn et al., 2001; Ganushkina and Pulkkinen, 2002). These models have, in principle, a possibility to separate between open drift paths (asymmetric ring current) and closed drift paths (symmetric ring current). However, this assumes that the electromagnetic fields are accurately given: that the magnetic field model gives the magnetopause at the appropriate distance, and that the electric field has a correct large-scale structure, including time variations. However, because the particle tracings are computationally very demanding, many models are limited to rather simple models for the electromagnetic fields. Thus, these models provide a complementary approach to the model developed in this paper. 


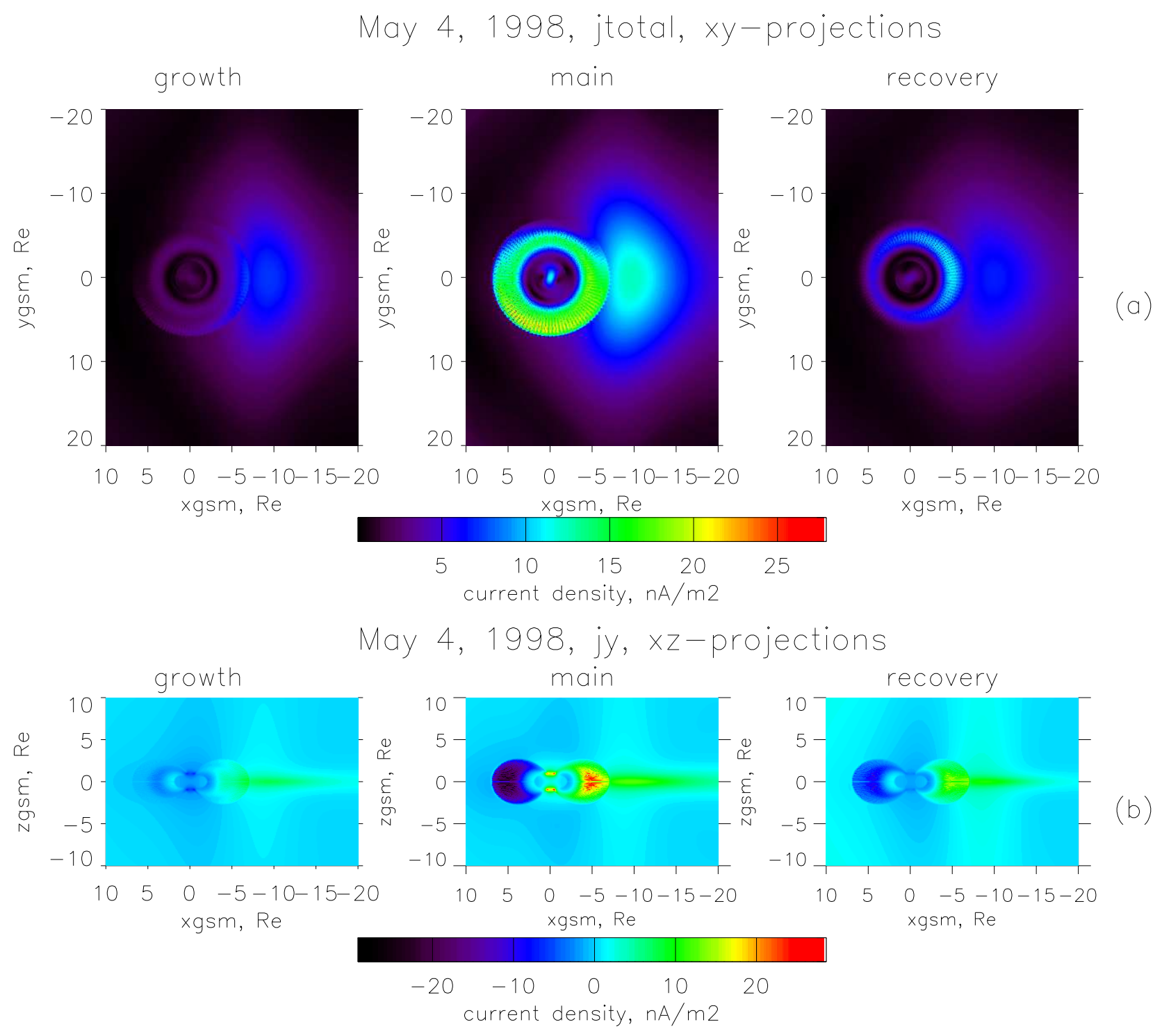

Fig. 12. The model current density in $\mathrm{nA} / \mathrm{m}^{2}$ in the (a) equatorial and (b) noon-midnight meridian planes for three moments during 4 May 1998 intense storm: (left) before the storm at 01:00 UT, (middle) at the storm main phase at 05:00 UT and (right) during the recovery phase at 10:00 UT.

An important feature of paraboloid model (Alexeev et al., 2001 ) is that it describes the magnetic field of each current system as a function of its own time-dependent parameters which are determined from satellite and ground-based data. Because both Alexeev's model and our models contain timedependent parameters, it would be very useful and interesting to compare the modelling results. It is planed to do the modelling of several storm events using both models in the near future. This will be a topic for another paper.

A third approach to defining the storm-time inner magnetosphere current distribution was adopted in the T02 model
(Tsyganenko, 2002a, b), which gives the magnetospheric state as a function of solar wind and IMF parameters, as well as the $D_{s t}$ index. This model continues the series of empirical models, which are based on the statistical determination of the model parameters as functions of the solar wind and IMF input and magnetospheric activity parameters. While this model has an accurate approximation for the ring current field, the Region 1 and 2 field-aligned current systems, as well as a realistic magnetopause shape, it does not include parameters to describe the substorm activity in the tail. Comparison of the two models during the storms shows that our 
model details faster field variations associated with substorm activity in the tail than the T02 model. Furthermore, it appears that the T02 model reproduces quite well the observed magnetic field during moderate storms, but during the very intense storm on 4 May 1998, the T02 model produced a very strong $B_{z}$ at GOES 8 and 9 of $-300 \mathrm{nT}$, instead of the observed $-100 \mathrm{nT}$. This is most probably caused by the very small number of such intense storms in the statistical database used to derive the model parameters. Thus, at times of highly atypical behavior, the event-oriented models, which adjust the parameters according to in-situ observations, can provide higher accuracy.

The time variations of the current systems during storms allows us to discuss one of the key open issues in storm research, namely the role of substorms in the storm evolution (see, e.g. McPherron, 1997). We have shown that the $A E$ enhancements are associated with strong intensification of the tail current, in a manner analogous to the isolated substorms (see, e.g. Baker et al., 1996). This would imply that most substorms during storms have similar tail current system development as during isolated substorms. This is consistent with the study of Pulkkinen et al. (1992), where a substorm during a moderate storm was found to have a current sheet that was located closer to the Earth and more intense than during isolated substorms, but the temporal evolution was quite similar. On the other hand, Pulkkinen et al. (2002) found that only a portion of the storm-time substorms behave similarly to the isolated ones. The auroral electrojet expanded sometimes poleward but in many cases also equatorward. The storm-time energetic particle fluxes show large fluctuations, quite different from isolated substorm injections (Reeves and Henderson, 2001). Using the time-evolving model developed here with a higher time resolution during storm-time substorms will allow us in the future to examine the storm-substorm relationship in more detail.

\section{Conclusions}

We presented an empirical, temporally evolving magnetic field model for storm periods. The model describes the ring current, the tail current, and the magnetopause currents with functions containing free parameters, whose values are defined for each time step separately based on in-situ measurements in the magnetosphere, on solar wind dynamic pressure, and on the ground-based storm index $D_{s t}$. We modeled the magnetic field evolution during four storms: 2 May and 4 May 1998, 10-12 October 1997, and 6-7 November 1997. The storm-time magnetic field model reproduced quite well large-scale variations of currents and magnetic field, while the smaller scale variations would require the introduction of localized currents not included in this model. Of the model parameters, the ring current intensity followed the $D_{s t}$ index and the tail current intensity followed the $A E$ index, which lends support to the conclusion that our model indeed reproduces the field variations associated with storms and substorms.
The model results show quite consistent behavior during the four modeled storms. The tail current intensifies first, and follows the drop in the $D_{s t}$ index. The ring current develops slower, and stays at an increased level longer than the tail current. During moderate storms $\left(D_{s t}>-100-150 \mathrm{nT}\right)$, both ring and tail currents are intensified, but the tail current contributes more to $D_{s t}$ than the ring current. On the other hand, during intense storms $\left(D_{s t}>-200 \mathrm{nT}\right)$, the tail current is intensified, but remains nearly constant, while the ring current follows the $D_{s t}$ variations. During these periods, the main contribution to the $D_{s t}$ index comes from the ring current. Thus, the information contained in the $D_{s t}$ index is different during small and large storms.

Acknowledgement. We would like to thank K. Ogilvie and R. Lepping for the use of WIND data in this paper, Interball-tail MIF$\mathrm{M}$ team for providing high resolution data (routinely produced by S. Romanov), World Data Center C2 for Geomagnetism, Kyoto, for the provisional $A E, K_{p}$ and $D_{s t}$ indices data. The data were obtained from the Coordinated Data Analysis Web (CDAWeb). GEOTAIL magnetic field data were provided by T. Nagai through DARTS at the Institute of Space and Astronautical Science (ISAS) in Japan. This work was supported by the Academy of Finland.

\section{References}

Alekseyev, I. I.: Regular magnetic field in the Earth's magnetosphere, Geomagnetism and Aeronomy, 18, 447-452, 1978.

Alexeev, I. I., Belenkaya, E. S., Kalegaev, V. V., Feldstein, Y. I., and Grafe: A. Magnetic storms and magnetotail currents, J. Geophys. Res., 101, 7737-7747, 1996.

Alexeev, I. I., Kalegaev, V. V., Belenkaya, Bobrovnikov, S. Y., Feldstein, Y. I., and Gromova, L. I.: Dynamic model of the magnetosphere: Case study for January 9-12, 1997, J. Geophys. Res., 106, 25 683-25 693, 2001.

Arykov, A. A. and Maltsev, Yu. P.: Contribution of various sources to the geomagnetic storm field, Geomagnetism and Aeronomy, 33, 771-775, 1994.

Baker, D. N., Pulkkinen, T. I.: Angelopoulos, V., Baumjohann, W., and McPherron, R. L. The neutral line model of substorms: Past results and present view, J. Geophys. Res., 101, 12 975-13 010, 1996.

Chen, M. W., Schulz, M., Lyons, L. R., and Gorney, D. J.: Stormtime transport of ring current and radiation belt ions, J. Geophys. Res., 98, 3835-3849, 1993.

Dessler, A. J. and Parker, E. N.: Hydromagnetic theory of magnetic storms, J. Geophys. Res., 64, 2239-2259, 1959.

Dremukhina, L. A., Feldstein, Y. I., Alexeev, I. I., Kalegaev, V. V., and Greenspan, M. E.: Structure of the magnetospheric magnetic field during magnetic storms, J. Geophys. Res., 104, $28351-$ $28360,1999$.

Ebihara, Yu. and Ejiri, M.: Simulation study on fundamental properties of the storm-time ring current, J. Geophys. Res., 105, $15843-15859,2000$.

Fok, M.-C. and Moore, T. E.: Ring current modeling in a realistic magnetic field configuration, Geophys. Res. Letters, 24, 17751778, 1997.

Ganushkina, N. Yu., Pulkkinen, T. I., and Kubyshkina, M. V.: Storm time ring current magnetic field modeling during May 15, 1997 event, Adv. Space Res., 30, 2175-2180, 2002a. 
Ganushkina, N. Yu., Pulkkinen, T. I., Kubyshkina, M. V., Singer, H. J., and Russell, C. T.: Modeling the ring current magnetic field during storms, J. Geophys. Res., 10.1029/2001JA900101, 02 July 2002 b.

Ganushkina, N. Yu., Pulkkinen, T. I., Kubyshkina, M. V., and Singer, H. J.: Comparative study of magnetospheric configuration changes during May 2, 1998 moderate storm and May 4, 1998 intense storm events, in Proceedings of Sixth International Conference on Substorms, edited by Winglee, R. M., University of Washington, Seattle, 483-488, 2002c.

Ganushkina, N. Yu., and Pulkkinen, T. I.: Particle tracing in the inner Earth's magnetosphere and the formation of the ring current during storm times, Advances in Space Research, 30, 18171820, 2002.

Garcia, H. A., and Spjeldvik, W. N.: Anisotropy characteristics of geomagnetically trapped ions, J. Geophys. Res., 90, 347-358, 1985.

Huttunen, K. E. J., Koskinen, H. E. J., and Schwenn, R.: Variability of magnetospheric storms driven by different solar wind perturbations, J. Geophys. Res., 107, 10.1029/2001JA900171, 02 July 2002.

Häkkinen, L. V. T., Pulkkinen, T. I., Nevanlinna, H., Pirjola, R. J., and Tanskanen, E. I.: Effects of induced currents on Dst and on magnetic variations at midlatitude stations, J. Geophys. Res., 107, SMP1-7, CitedID 1014, DOI 10.1029/2001JA900130, 2002.

Jordanova, V. K., Kozyra, J. U., Nagy, A. F., and Khazanov, G. V.: Kinetic model of the ring current-atmosphere interactions, J. Geophys. Res., 102, 14279-14 291, 1997.

Le, G., Russell, C. T., and Takahashi, K.: Morphology of the ring current derived from magnetic field observations, accepted for publications to Annales Geophysicae, 2003.

Liemohn, M. W., J. U. Kozyra, M. F. Thomsen, A. J. Ridley, G. Lui, J. E. Borovsky, and Cayton, T. E.: Dominant role of the asymmetric ring current in producing the stormtime Dst*, J. Geophys. Res., 106, 10 883-10 904, 2001.

Lui, A. T. Y., McEntire, R. W.; Krimigis, S. M.: Evolution of the ring current during two geomagnetic storms, J. Geophys. Res., 92, 7459-7470, 1987.

Lui, A. T. Y. and Hamilton, D.C.: Radial profiles of quiet time magnetospheric parameters, J. Geophys. Res., 97, 19325-19332, 1992.

McPherron, R. L.: The role of substorms in the generation of magnetic storms, in: Geomagnetic Storms, Geophysical Monograph 98, edited by Tsurutani, B. T., Gonzalez, W. D., Kamide, Y., and Arballo, J. K., 131-147, 1997.

Milillo, A., Orsini, S., Delcourt, D. C., Mura, A., Massetti, S., De Angelis, E., and Ebihara, Y.: Empirical model of proton fluxes in the equatorial inner magnetosphere: 2. Properties and applications, J. Geophys. Res., 108, 2002JA009581, 2003.
Pulkkinen, T. I., Baker, D. N., Pellinen, R. J., Buchner, J., Koskinen, H. E. J., Lopez, R. E., Dyson, R. L., and Frank, L. A.: Particle scattering and current sheet stability in the geomagnetic tail during the substorm growth phase, J. Geophys. Res., 97, 19283 $19297,1992$.

Pulkkinen, T. I., Koskinen, H. E. J., Huttunen, K. E. J., Kauristie, K., Tanskanen, E. I., Palmroth, M., and Reeves, G. D.: Effects of magnetic storms on substorm evolution, Sixth International Conference on Substorms, edited by R. M. Winglee, University of Washington, Seattle, 2002, 464-471.

Reeves, G. D., and Henderson, M. G.: The storm-substorm relationship: Ion injections in geosynchronous measurements and composite energetic neutral atom images, J. Geophys. Res., 106, 5833-5844, 2001.

Roederer, J. G.: Dynamics of geomagnetically trapped radiation, 36 pp., Springer-Verlag, New York, 1970.

Russell, C. T., Le, G., Chi, P., et al.: The extreme compression of the magnetosphere on May 4, 1998, as observed by the Polar spacecraft, Adv. Space Res., 25, 1369-1375, 2000.

Sckopke, N.: A general relation between the energy of trapped particles and the disturbance field near the Earth, J. Geophys. Res., 71, 3125-3130, 1966.

Shue, J.-H., Song, P., Russell, C. T., et al.: Magnetopause location under extreme solar wind conditions, J. Geophys. Res., 103, 17 691-17 700, 1998.

Tsyganenko, N. A.: Global quantitative models of the geomagnetic field in the cislunar magnetosphere for different disturbance levels, Planet. Space Sci., 35, 1347-1358, 1987.

Tsyganenko, N. A.: A magnetospheric magnetic field model with a warped tail current sheet, Planet. Space Sci., 37, 5-20, 1989.

Tsyganenko, N. A.: Modeling the Earth's magnetospheric magnetic field confined within a realistic magnetopause, J. Geophys. Res., 100, 5599-5612, 1995.

Tsyganenko, N. A.: A model of the near magnetosphere with a dawn-dusk asymmetry: 1. Mathematical structure, J. Geophys. Res., 107, SMP 12-1, CiteID 1179, DOI 10.1029/2001JA0002192001, 2002a.

Tsyganenko, N. A.: A model of the near magnetosphere with a dawn-dusk asymmetry: 2. Parameterization and fitting to observations, J. Geophys. Res., 107, SMP 10-1, CiteID 1176, DOI 10.1029/2001JA000220, 2002b.

Turner, N. E., Baker, D. N., Pulkkinen, T. I., and McPherron, R. L.: Evaluation of the tail current contribution to $D_{s t}$, J. Geophys. Res., 105, 5431-5439, 2000. 